\title{
Blood leukocytes from benznidazole-treated indeterminate chagas disease patients display an overall type-1-modulated cytokine profile upon short-term in vitro stimulation with trypanosoma cruzi antigens
}

Renato Sathler-Avelar ${ }^{1,2,3,5,6^{*}}$, Danielle Marquete Vitelli-Avelar ${ }^{1,5}$, Silvana Maria Elói-Santos ${ }^{4,5}$, Eliane Dias Gontijo ${ }^{4,5}$, Andréa Teixeira-Carvalho ${ }^{1,5}$ and Olindo Assis Martins-Filho ${ }^{1,5}$

\begin{abstract}
Background: Benznidazole (Bz)-chemotherapy is recommended to prevent Chagas disease progression, despite its limited efficacy during chronic disease. However, the host mechanisms underlying these benefits still remain to be elucidated.

Methods: In this study, we have used short-term whole blood cultures to describe the cytokine profile of Bztreated Indeterminate Chagas disease patients-(INDt) as compared to untreated patients-(IND).

Results: Our findings showed that IND presented increased levels of IL- $10^{+}$neutrophils, IL-12 $2^{+}$and IL- $10^{+}$monocytes and IFN- $\gamma^{+} \mathrm{NK}$-cells. Moreover, IND showed slight increase of IL-4 $4^{+} \mathrm{CD} 4^{+} \mathrm{T}$-cells and enhanced levels of IL-10 $\mathrm{CD} 8^{+} \mathrm{T}$-cells and B-cells. Additional analysis of cytokine Low and High producers also highlighted the presence of High cytokine producers within IND, including IL-10 from CD4+ T-cells and IFN- $\gamma$ from CD8 ${ }^{+}$T-cells, as compared to NI. The Bztreatment lead to an overall cytokine down-regulation in the innate and adaptive compartments, including low levels of

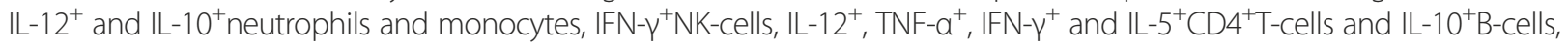
along with basal levels of cytokine-expressing $\mathrm{CD} 8^{+} \mathrm{T}$-cells in INDt as compared to IND. The in vitro antigen stimulation shifted the cytokine profile toward a type 1-modulated profile, with increased levels of $\mathrm{IL}-12^{+}$and $\mathrm{IL}-10^{+}$ monocytes, IFN- $\gamma^{+}$and IL-4 ${ }^{+} \mathrm{NK}$-cells along with TNF- $\mathrm{a}^{+}$and IFN- $\gamma^{+} \mathrm{CD} 8^{+} \mathrm{T}$-cells. Analysis of Low and High cytokine producers, upon in vitro antigen stimulation, further confirm these data.
\end{abstract}

Conclusion: Together, our findings showed that the Bz treatment of Indeterminate Chagas' disease patients shifts the cytokine patterns of peripheral blood monocytes, NK-cells and CD8 ${ }^{+}$T-cells towards a long-lasting Type-1-modulated profile that could be important to the maintenance of a non-deleterious immunological microenvironment.

Keywords: Chagas disease, Benznidazole, Immune response, Cytokines, Leucocytes subsets

Sponsorships: CNPq, FAPEMIG, FIOCRUZ

\footnotetext{
* Correspondence: avelar@cpqrr.fiocruz.br

'Laboratório de Biomarcadores de Diagnóstico e Monitoração, CPqRR-

FIOCRUZ, Belo Horizonte, MG, Brazil

2Unicentro Newton Paiva, Belo Horizonte, MG, Brazil

Full list of author information is available at the end of the article
} 


\section{Background}

An outstanding triumph of the Brazilian medicine was the discovery of Chagas disease by Carlos Chagas at the beginning of the $20^{\text {th }}$ century. One century after the discovery, several aspects of Chagas disease still remain unclear, including those regarding to the multiple events of pathogenesis underlying the clinical progression, as well as the mechanisms implicated in the successful etiological treatment.

Chagas disease is caused by the haemoflagellate protozoan Trypanosoma cruzi and is considered one of the most important public health problems in Latin America, affecting approximately 8 to 10 million people and a further 100 million people are considered at risk of infection [1].

The major mechanism associated with Chagas disease pathology is the continuous inflammatory infiltrate observed mainly in the cardiac and digestive tract organs characterized by damages in the neuronal conductive systems and also by muscle cytolysis [2]. There is a growing consensus that complex co-adaptation between the persistent parasite infection and the balanced host immune response underlies the establishment of Indeterminate clinical form of Chagas disease. On the hand the persistence of parasite along with unbalanced immune response leads to a sustained inflammatory response that supports these characteristic lesions of chronic Chagas disease [2]. In this immunopathogenesis paradigm the eradication of $T$. cruzi may be a prerequisite to control the disease progression and prevent the irreversible long-term consequence of Chagas disease. Therefore, Chagas disease must be treated primarily as an infectious disease, and not as autoimmune disorder, in contrast to long-held views [3].

Specific chemotherapy is recommended for the treatment of Chagas disease applying the general assumption that the earlier the specific treatment is initiated greater are the chances of parasitological cure and clinical benefits to the host [4]. At present, Chagas disease chemotherapy is restricted to two drugs, Benznidazole $(\mathrm{Bz})$ and nifurtimox (Nfx). In Brazil, only $\mathrm{Bz}$ has been used to etiological treatment of Chagas disease [5] with higher cure ratio observed during acute, congenital and early chronic Indeterminate Chagas disease [4-6]. Despite the low cure rates observed in most patients submitted to treatment during chronic Chagas disease, several studies have suggested that the Bz-treatment should be still recommended during chronic Chagas disease, since it prevents the disease progression, regardless of lack of complete parasite clearance [7-9]. The mechanism of action of benznidazole is not completely clear. It has been proposed that the BZ-mediated trypanocidal mechanism is effective because the nitro group is reduced by parasite enzymes to produce free radicals, superoxide anions, and hydrogen peroxide [10]. One of the major factors potentially influencing the parasite clearance as well as the morbidity control following the treatment for Chagas' disease is the cooperative action between the drug effects and the host immunological response [11-14]. However little is known about the changes in the host immune following $\mathrm{Bz}$ treatment, specifically during chronic Indeterminate Chagas disease that could synergistically act with the BZ-therapy. The coherent understanding of these changes will certainly support the development of new protocol for Bz therapy, intervention and management of chronic Chagas disease. We believe that the analysis of host immunity status pre- and post-treatment is essential to further elucidate the impact of $\mathrm{Bz}$ intervention as well as support the rational development of new trypanosomicidal agents. We have previously shown that early after the end of the Bz therapy, the NK-cells and CD8 ${ }^{+}$T-lymphocytes are important sources of IFN- $\gamma$ and that IL-10 produced by $\mathrm{CD} 4{ }^{+} \mathrm{T}$-cells and B lymphocytes are putative key element to modulate the immune response and control tissue damage might inducible by the pro-inflammatory response. In the current investigation we would like to test the hypothesis that the Bz-therapy modulates the immune response inducing a long-lasting impact on the immunological status of treated patients, inducing a similar Type- 1 modulated cytokine profile as observed early after the end of the treatment [13,14].

Our findings bring new insights to the hypothesis that later on after the end of Bz-treatment, the patients presented a down-regulated cytokine pattern along with the capacity to build a Type-1 modulated cytokine response, upon $T$. cruzi antigen stimuli, supported by proinflammatory cytokine from monocytes, $\mathrm{NK}$ and $\mathrm{CD} 8^{+}$ T-cells, counterbalanced by IL-10 from monocytes.

\section{Methods \\ Study population}

This cross-sectional study involved 47 subjects classified into three groups referred as IND - untreated Indeterminate Chagas disease patients $(\mathrm{n}=15 ; 3$ males and 12 females; mean age $=42.5 \pm 5.5$ years, ranging from $35-52$ years); INDt - Bz-treated Indeterminate Chagas disease patients $(\mathrm{n}=14 ; 4$ males and 10 females; mean age $=44.0 \pm 8.7$ years, ranging from 33-56 years) and NI - non-infected individuals $(\mathrm{n}=18,7$ males and 11 females, mean age $=29.0 \pm 9.7$ years, ranging from $18-47$ years).

Indeterminate Chagas disease was diagnosed by at least two positive results on serological tests (indirect hemagglutination, indirect immunofluorescence, or enzyme-linked immunosorbent assay) and no alteration in the clinical and physical examination, besides normal electrocardiogram, chest X-ray, Holter, and echodopplercardiography profiles. The IND patients were recruited 
at the Ambulatório de doença de Chagas, Hospital das Clínicas, Universidade Federal de Minas Gerais (Belo Horizonte, Minas Gerais, Brazil).

Benznidazole (N-benzyl-2-nitro-1-imidazolacetamide) treatment was carried out in daily doses of $5 \mathrm{mg} / \mathrm{kg}$ of body weight, twice a day for 60 days, according to the Brazilian Ministry of Health [15]. The INDt patients were recruited seven years after the end of etiological treatment at the Ambulatório de doença de Chagas, Hospital das Clínicas, Universidade Federal de Minas Gerais (Belo Horizonte, Minas Gerais, Brazil).

The non-infected subjects showing negative serologic tests for antibodies against T. cruzi were contacted at the Centro de Hematologia e Hemoterapia de Minas Gerais (Belo Horizonte, Minas Gerais, Brazil).

All study participants provided written informed consent following the guidelines of Ethics Committee of the Minas Gerais Federal University. The study protocol complied with the regulations 196/1996 of Brazilian National Council on Research in Humans and was also approved by the Ethical Committee of Minas Gerais Federal University under protocol \# COEP-ETIC 070/00.

\section{Blood samples}

Five milliliters of whole peripheral blood were collected in EDTA anticoagulant for hemogram analysis. Ten milliliters of heparinized peripheral blood were collect from each participant and used for short-term in vitro culture of whole blood. Heparin whole blood samples were maintained at room temperature for up to 12 hours prior processing.

\section{Trypanosoma cruzi epimastigote antigen preparation}

Soluble Epimastigote Antigen (EPI) was prepared from a stationary phase Y strain T. cruzi epimastigotes grown in LIT-medium. After the third or fourth in vitro passage, epimastigotes were harvested, washed in $15 \mathrm{mM}$ phosphate-buffered saline (PBS), $\mathrm{pH}$ 7.4, and resuspended to $10^{8}$ cells $/ \mathrm{mL}$ in $15 \mathrm{mM}$ PBS, pH 7.4. The suspension was rapidly frozen at $-70^{\circ} \mathrm{C}$ and thawed at $37^{\circ} \mathrm{C}$ three times, with a sonication procedure between each step. The crude lysate was centrifuged $(37,000 \mathrm{~g})$ for $90 \mathrm{~min}$ and the supernatant collected, dialysed overnight against $15 \mathrm{mM}$ PBS, $\mathrm{pH}$ 7.4, sterilized by filtration through a $0.22-\mu \mathrm{m}$ pore membrane (Filter millex, Milipore Products Division, Billerica, MA, USA) and stored at $-70^{\circ} \mathrm{C}$ until use. The protein content was assayed by the method described by Lowry et al. [16].

\section{Short-term in vitro culture of whole blood}

Short-term cultures in vitro were carried out as previously described by Sathler-Avelar et al., [14]. Briefly, $500 \mu \mathrm{L}$ aliquots of heparinized whole blood samples were transferred into $14 \mathrm{~mL}$ polypropylene tubes (Falcon ${ }^{\circledR}$, BD Pharmingen, San Jose, CA, USA) and incubated in the presence of $500 \mu \mathrm{L}$ of RPMI-1640 (GIBCO, Grand Island, NY, USA) - "Control Culture"; $500 \mu \mathrm{L}$ aliquots of heparinized whole blood samples in the presence of EPI soluble antigen at a final concentration of $20 \mu \mathrm{g} / \mathrm{mL}$ in RPMI-1640 - "Stimulated Culture" or Phorbol 12Myristate 13-Acetate at $25 \mathrm{ng} / \mathrm{mL}$ plus ionomycin at $1 \mu \mathrm{g} / \mathrm{mL}$ (Sigma, St Louis, MO, USA) in RPMI-1640 "PMA stimulated culture". The Control and Stimulated cultures were pre-incubated for $1 \mathrm{~h}$ at $37^{\circ} \mathrm{C}, 5 \% \mathrm{CO}_{2}$ in a humidified incubator. Afterward, all cultures were incubated for $4 \mathrm{~h}$ in at $37^{\circ} \mathrm{C}, 5 \% \mathrm{CO}_{2}$ in a humidified incubator in the presence of BFA at $10 \mu \mathrm{g} / \mathrm{mL}$. Following incubation, all cultures were treated with $100 \mu \mathrm{L}$ of EDTA $2 \mathrm{mM}$ in PBS for 15 min (Sigma, St Louis, MO, USA) in order to block the activation process.

\section{Immunophenotyping for cell subsets and intracellular cytokines analysis}

Following the short term in vitro stimulation, all cultures were washed once with $3 \mathrm{~mL}$ of FACS buffer prepared as PBS supplemented with $0.5 \%$ bovine serum albumin and $0.1 \%$ sodium azide (Sigma, St Louis, MO, USA). Samples were resuspended into $1 \mathrm{~mL}$ of FACS buffer. Aliquots of $400 \mu \mathrm{L}$ were immunostained in the dark for $30 \mathrm{~min}$ at room temperature with $10 \mu \mathrm{L}$ of pre-diluted TriColor-labelled monoclonal antibodies (mAbs) antiCD4, CD8, CD14, CD16 or CD19 (Caltag, Burlingame, CA, USA). Following incubation, the erythrocyte lysing and cell fixation procedures were performed by adding $2 \mathrm{~mL}$ of FACS lysing solution (BD, San Diego, CA, USA) and incubation for $30 \mathrm{~min}$ at room temperature. Membrane-stained leucocytes were permeabilized with $3 \mathrm{~mL}$ of FACS perm-buffer for $10 \mathrm{~min}$ at room temperature (FACS buffer supplemented with $0.5 \%$ saponin) and washed once with $2 \mathrm{~mL}$ of FACS buffer. Cell suspension aliquots of $30 \mu \mathrm{L}$ were transferred to 96 wells round bottom microplates (Falcon ${ }^{\circledR}$; BD Pharmingen, San Jose, CA, USA) were stained for $30 \mathrm{~min}$ at room temperature, in the dark in the presence of $20 \mu \mathrm{L}$ of PElabelled anti-cytokine mAbs (IL-12, TNF- $\alpha$, IFN- $\gamma$, IL-4, IL-5 and IL-10). All antibodies were diluted 1:50 in FACS perm-buffer and were purchased from BD Pharmingen (San Diego, CA, USA). After intracytoplasmic cytokine staining, the cells were washed twice with $200 \mu \mathrm{L}$ of FACS perm-buffer and FACS buffer, respectively, and then fixed in $200 \mu \mathrm{L}$ of FACS FIX Solution (10 g/L of paraformaldehyde, $10.2 \mathrm{~g} / \mathrm{L}$ of sodium cacodilate and $6.63 \mathrm{~g} / \mathrm{L}$ of sodium chloride, $\mathrm{pH} 7.2$, all from Sigma, St Louis, MO, USA). The samples were stored at $4{ }^{\circ} \mathrm{C}$ prior flow cytometry acquisition and analysis.

\section{Flow cytometry acquisition and analysis}

Flow cytometry acquisition of 30,000 immunestained cells/samples were performed in a FACScalibur ${ }^{\circledR}$ flow 
cytometer equipped with CELLQUEST ${ }^{\mathrm{TM}}$ software (Becton Dickinson, San Jose, CA, USA). Distinct gating strategies were used to analyze the cytokine-expressing leucocyte subpopulations from the innate (monocytes, neutrophils and NK-cells) and adaptive immunity (lymphocytes as well as T- and B-cell subsets). The monocytes were selected as $\mathrm{CD} 14^{\mathrm{High}+}$ cells and the neutrophil as SSC ${ }^{\text {High }} \mathrm{CD} 14^{\text {Low+ }}$ cells on FL3/anti-CD14TC versus SSC/laser side-scatter dot plots. The lymphocyte populations were selected on FSC/laser forward-scatter versus SSC/laser side-scatter dot plots. Following the initial gate selection, the frequencies of cytokine $^{+}$cells were quantified by quadrant statistics applied on FSC/laser forward-scatter versus FL2/anticytokine-PE dot plots for monocytes and neutrophils and FL3/anti-CD16, CD4, CD8 or CD19 TC versus FL2/ anti-cytokine-PE dot plots for NK-cells, T-lymphocyte subsets and B-cells.

\section{Analysis of low and high cytokine-producers}

The analysis of cytokine-producers within IND and INDt groups were performed by first taking the median value of cytokine ${ }^{+}$cells from each leucocyte subpopulation (neutrophils, monocytes, NK-cells, CD4 $4^{+}$and $\mathrm{CD}^{+}$ T-cells and B-cells) from the NI group as the cut-off edge to categorize the subjects as Low and High cytokine-producers. Gray-scale diagrams were used to assemble the prevalence of Low (empty rectangle), High inflammatory (black rectangle for IL-12, TNF- $\alpha$ and IFN- $\gamma$ ) or High regulatory (gray rectangle for IL-4, IL-5 and IL-10) cytokine-producers amongst IND and INDt groups. Bar charts were applied to compile the frequency of Low and High cytokine-producers within each leucocyte subset.

\section{Statistical analysis}

Statistical analysis was performed using the GraphPad Prism 5 software package (San Diego, CA, USA). As all data files assume a non-Gaussian distribution, statistical comparisons were carried out using the nonparametric Kruskal-Wallis test followed by Dunns multiple comparison test to evaluate the cytokine profiles among NI, IND and INDt groups. The comparative analyses between control culture and stimulated culture were performed by Wilcoxon matched pairs test. The frequency of high and low cytokine-producers was compared by contingency table analysis by Chi-square test. The differences were considered significant when $\mathrm{p}$-values were $<0.05$.

\section{Results}

\section{Cytokine profile of innate immunity in indeterminate chagas disease patients}

The number of inflammatory and regulatory cytokines, expressed by the innate immunity cells, from Indeterminate Chagas disease patients is shown in Figure 1.
Data from the control culture showed a prominent anti-inflammatory cytokine pattern in neutrophils from IND as compared to NI, represented by enhanced levels of $\mathrm{IL}-10^{+}$cells and basal levels of $\mathrm{IL}_{-} 12^{+}$cells (Figure 1A, left panel). Upon in vitro antigen stimulation, a similar anti-inflammatory cytokine profile was observed in IND, with increased number of IL- $10^{+}$neutrophils as compared to the NI and control culture (Figure 1A, right panel).

The analyses of monocytes reveled a mixed inflammatory/anti-inflammatory cytokine pattern in IND as compared to NI, with increased levels of $\mathrm{IL}-12^{+}$and $\mathrm{IL}-10^{+}$ cells (Figure 1B, left panel). This mixed profile was preserved after in vitro antigen stimulation, as shown by the increased number of $\mathrm{IL}-12^{+}$and $\mathrm{IL}-10^{+}$monocytes in IND as compared to NI (Figure 1B, right panel).

Analysis of NK-cells showed a predominant inflammatory cytokine pattern in IND, with higher number of IFN- $\gamma^{+}$ cells and basal levels of $\mathrm{IL}_{-} 4^{+}$cells as compared to NI (Figure $1 \mathrm{C}$, left panel). Upon in vitro antigen stimulation, despite no difference in the number of IFN- $\gamma^{+}$cells, the lower levels of IL- $4^{+}$cells count to the predominant inflammatory cytokine pattern of NK-cells observed in IND as compared to NI (Figure 1C, right panel).

Impact of bz-treatment on the cytokine pattern of innate immunity of indeterminate chagas disease patients

In order to investigate the impact of etiological treatment on the cytokine profile of innate immunity of Indeterminate Chagas disease patients, we have compared the cytokine profile of neutrophils, monocytes and NK-cells from INDt as compared to IND. These differences are highlighted by connecting lines.

Data analyses showed an overall cytokine downregulation in the innate immunity compartment after benznidazole therapy, as shown by the lower levels of $\mathrm{IL}-12^{+}, \mathrm{IL}-10^{+}$neutrophils and monocytes, as well as reduced levels of IFN- $\gamma^{+}$NK-cells in INDt as compared to IND (Figure 1A, B and C, left panel).

However, the in vitro antigen stimulation was able to shift the cytokine expression by monocytes and NK-cells toward a type 1-regulated immune profile, with increased levels of IL-12 and IFN- $\gamma$ respectively counterbalanced by IL-10 from monocytes (Figure 1B and C, right panel), despite no changes in the cytokine profile of neutrophils (Figure 1A, right panel).

\section{Cytokine profile of adaptive immunity in indeterminate chagas disease patients}

The levels of inflammatory and regulatory cytokineexpressing cells in the adaptive immunity compartment from Indeterminate Chagas disease patients are shown in Figures 2, 3 and 4. 

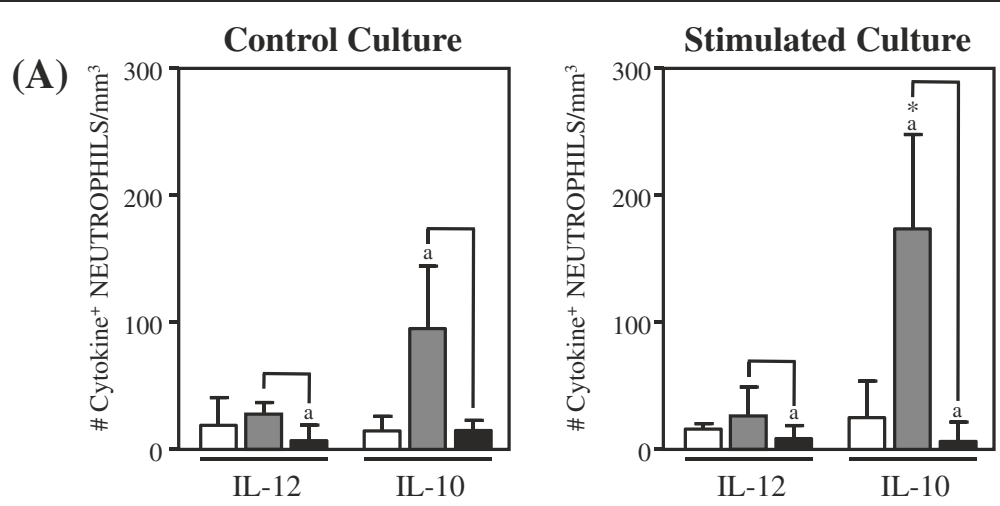

(B)

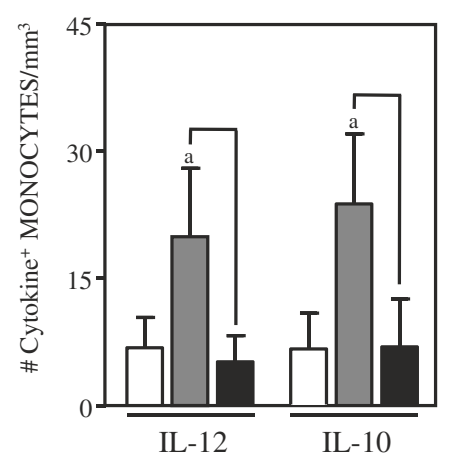

(C)

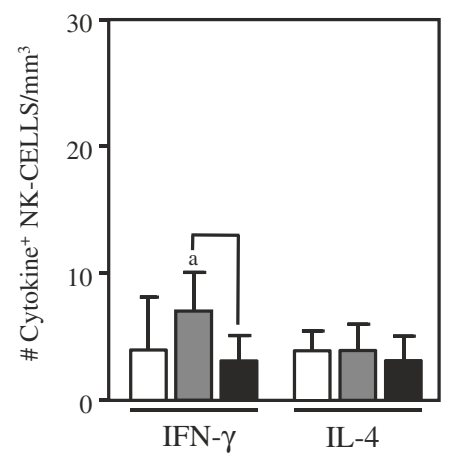

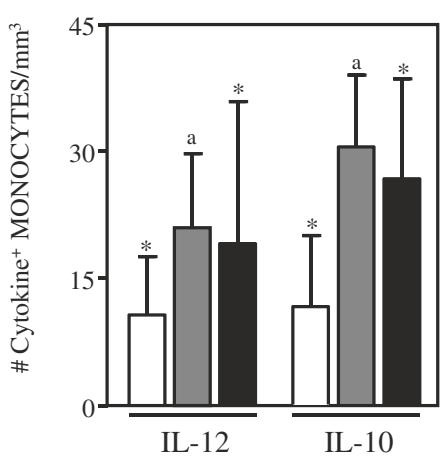

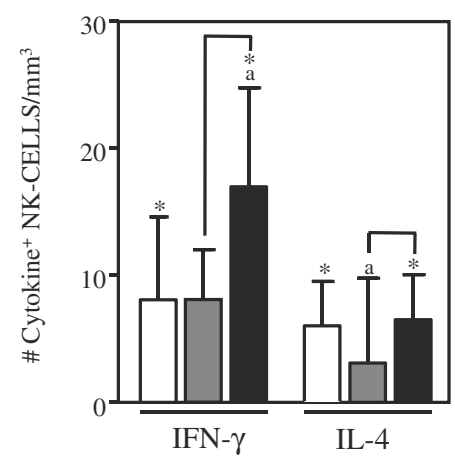

Figure 1 Analysis of intracytoplasmic cytokine profile of neutrophils. (A), monocytes (B) and NK-cells in the peripheral blood from non treated Indeterminate chagasic patients (IND gray rectangle), Bz-treated Indeterminate chagasic patients (INDt black rectangle) as compared to non-infected individual ( $\mathrm{Nl}$ empty rectangle). Data are expressed as median absolute counts plus the interquartile range of cytokine ${ }^{+}$cells observed after short-term in vitro "Control Culture" (left panels) and T. cruzi epimastigote antigen "Stimulated Culture" (right panels) of wholeblood samples. Cytokine ${ }^{+}$neutrophils, monocytes and NK-cells were quantified by dual color immunophenotyping (anti-CD14-TC or anti-CD16-TC plus anti-cytokine-PE mAbs) using specific gate strategies to select each leucocyte subset, as described in Material and Methods. The significant differences at $\mathrm{p}<0.05$ for comparisons with $\mathrm{NI}$ are indicated by the letter ' $a$ '. The significant differences at $p<0.05$ for comparisons with INDt are indicated by connecting lines. The significant differences at $p<0.05$ for comparative analysis between "Control" and "Stimulated" cultures are indicated by *.

Data from the control culture showed a small shift towards a anti-inflammatory cytokine pattern in $\mathrm{CD} 4^{+}$ T-lymphocytes from IND as compared to NI, represented by a slight increase in the number of IL- $4^{+}$along with the basal numbers of TNF- $\alpha^{+}, \mathrm{IL}-12^{+}, \mathrm{IFN}-\gamma^{+}, \mathrm{IL}-5^{+}$ and $\mathrm{IL}-10^{+}$cells (Figure 2A). Upon in vitro antigen stimulation despite the general basal levels of cytokines observed for $\mathrm{CD} 4^{+}$T-cells, the small decrease in the $\mathrm{IL}-12^{+}$cells could support the small shift towards a anti-inflammatory cytokine pattern in $\mathrm{CD} 4^{+}$T-lymphocytes.

A typical anti-inflammatory cytokine profile was observed for both $\mathrm{CD}^{+}$T-lymphocytes and B-cells from IND as compared to NI, represented by increased levels of IL- $10^{+}$ cells along with a lower number of $\mathrm{TNF}-\alpha^{+} \mathrm{B}$-cells 
(A)

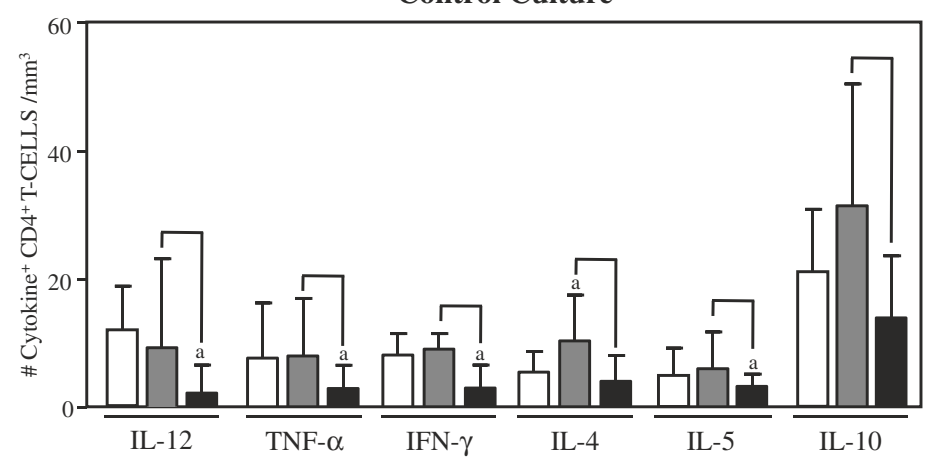

(B)

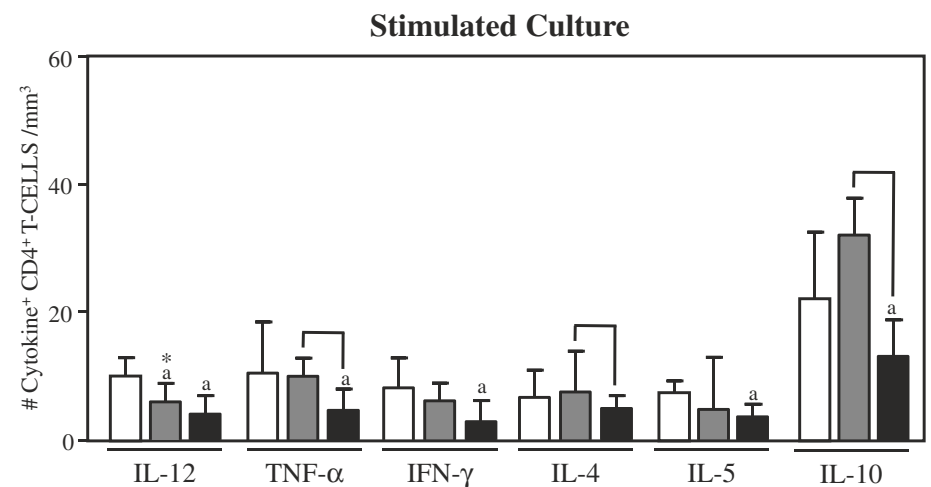

Figure 2 Analysis of intracytoplasmic cytokine profile of CD4 $4^{+}$. T-lymphocytes in the peripheral blood from untreated Indeterminate chagasic patients (IND gray rectangle), Bz-treated Indeterminate chagasic patients (INDt black rectangle) as compared to non-infected individual (NI empty rectangle). Data are expressed as median absolute counts plus the interquartile range of cytokine ${ }^{+}$cells observed after short-term in vitro "Control Culture" (top panel) and T. cruzi epimastigote antigen "Stimulated Culture" (bottom panel) of whole-blood samples. Cytokine $\mathrm{CD}^{+}$T-cells were quantified by dual color immunophenotyping (anti-CD4-TC plus anti-cytokine-PE mAbs) using specific gate strategy, as described in Material and Methods. The significant differences at $p<0.05$ for comparisons with $\mathrm{NI}$ are indicated by the letter ' $a$ '. The significant differences at $p<0.05$ for comparisons with INDt are indicated by connecting lines. The significant differences at $p<0.05$ for comparative analysis between "Control" and "Stimulated" cultures are indicated by *.

(Figure 3A and 4A). Upon in vitro antigen stimulation, despite the increased number of IFN- $\gamma^{+} \mathrm{CD} 8^{+}$T-lymphocytes and TNF- $\alpha^{+}$B-cells observed in comparison to the control culture, a anti-inflammatory cytokine profile still remain preponderant in both $\mathrm{CD}^{+}$T-lymphocytes and B-cells from IND as compared to NI (Figures $3 \mathrm{~B}$ and $4 \mathrm{~B}$ ).

\section{Impact of bz-treatment on the cytokine pattern of adaptive immunity of indeterminate chagas disease patients}

The comparative analysis of cytokine-expressing cells in the adaptive immunity compartment after the etiological treatment is shown in Figures 2, 3 and 4.

Data from the control culture showed an overall cytokine down-regulation in $\mathrm{CD} 4^{+}$T-cells from INDt as compared with IND and NI, with decreased levels of IL- $12^{+}, \mathrm{TNF}-\alpha^{+}, \mathrm{IFN}-\gamma^{+}$and IL- $5^{+}$cells, along with basal numbers of IL- $4^{+}$and IL- $10^{+}$cells (Figure 2A) with no changes observed after the in vitro antigen stimulation (Figure 2B).
On the other hand, despite the basal levels of cytokine-expressing $\mathrm{CD}^{+} \mathrm{T}$-cells observed in the control cultures from INDt as compared to IND (Figure $3 \mathrm{~A}$ ), the in vitro antigen stimulation was able to drive the $\mathrm{CD}^{+} \mathrm{T}$-cells towards a inflammatory cytokine profile, with increased numbers of TNF- $\alpha^{+}$and IFN- $\gamma^{+}$ $\mathrm{CD}^{+}$T-cells in INDt as compared to IND and NI (Figure 3B).

Data analysis from the control cultures also showed a cytokine down-regulation in B-cells from INDt as compared with IND and NI, with decreased levels of IL- $10^{+}$ cells (Figure 4A) which remain after in vitro antigen stimulation, regardless of slight increase in TNF- $\alpha^{+}$ B-cells observed in comparison to the control culture (Figure 4B).

\section{Analysis of low and high cytokine-producers amongst indeterminate chagas disease patients}

As previously report by Bahia-Oliveira et al. [17] and Vitelli-Avelar et al. [18], the analysis of Low and High 
(A)

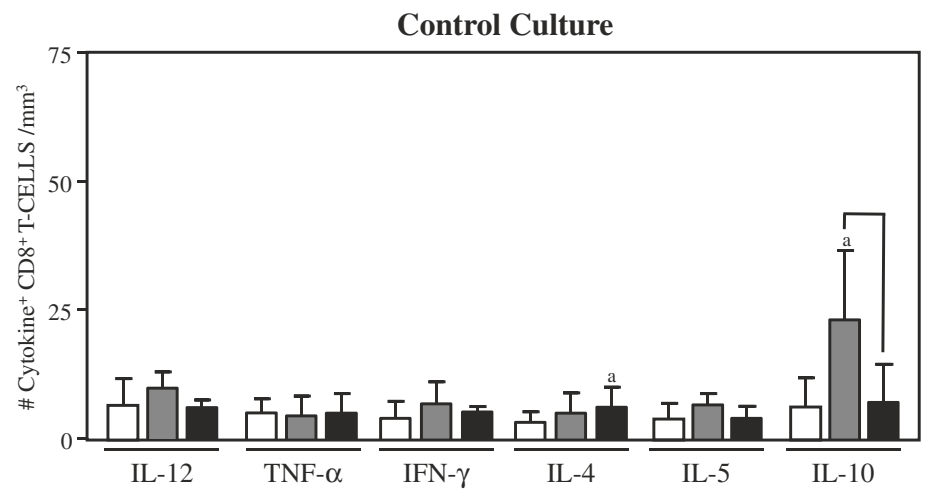

(B)

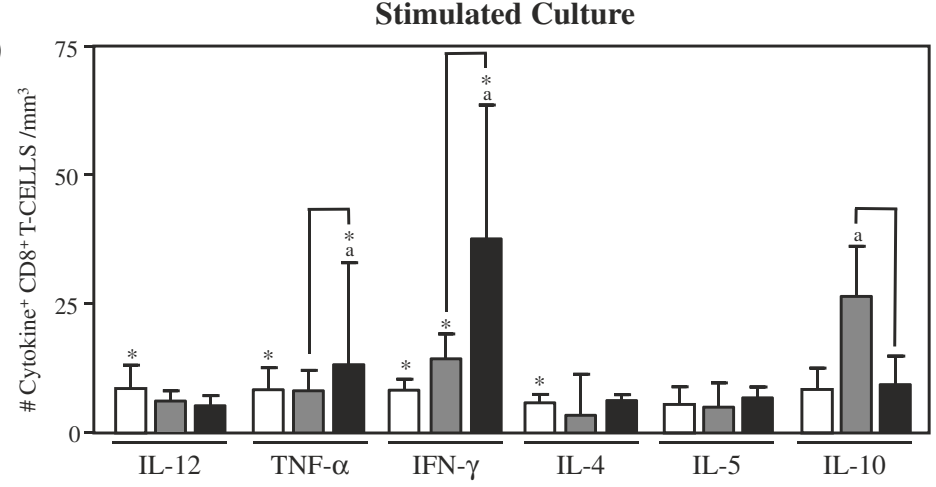

Figure 3 Analysis of intracytoplasmic cytokine profile of CD8 $\mathbf{8}^{+}$. T-lymphocytes in the peripheral blood from untreated Indeterminate chagasic patients (IND gray rectangle), Bz-treated Indeterminate chagasic patients (INDt black rectangle) as compared to non-infected individual (NI empty rectangle). Data are expressed as median absolute counts plus the interquartile range of cytokine ${ }^{+}$cells observed after short-term in vitro "Control Culture" (top panel) and T. cruzi epimastigote antigen "Stimulated Culture" (bottom panel) of whole-blood samples. Cytokine $\mathrm{CD}^{+}$T-cells were quantified by dual color immunophenotyping (anti-CD8-TC plus anti-cytokine-PE mAbs) using specific gate strategy, as described in Material and Methods. The significant differences at $p<0.05$ for comparisons with $\mathrm{NI}$ are indicated by the letter ' $a$ '. The significant differences at $p<0.05$ for comparisons with INDt are indicated by connecting lines. The significant differences at $p<0.05$ for comparative analysis between "Control" and "Stimulated" cultures are indicated by *.

cytokine-producers represents a powerful tool to characterize distinct immunological profiles in Chagas disease patients (Figure 5A and B, top panels). The frequencies of High cytokine-producers in the IND and INDt groups were obtained considering the median of a given cytokine ${ }^{+}$cells from the NI group as the cut-off edge to categorize the subjects as Low and High cytokine-producers. We have used gray-scale diagrams to assemble the frequency of Low (empty rectangle), High inflammatory (black rectangle) and regulatory (gray rectangle) cytokine-producers amongst IND and INDt groups. Using this concept, our data confirmed the presence of a type-1 modulated cytokine profile within innate immunity cells, with enhanced frequency of High cytokine producers, including IL-10 from neutrophils, IL-12 and IL-10 from monocytes and IFN- $\gamma$ from NK-cells. The analysis of the adaptive compartment also confirmed the presence of a predominant anti-inflammatory immune response in $\mathrm{CD} 4^{+}, \mathrm{CD} 8^{+}$ and $\mathrm{B}$-cells and additionally pointed out the presence of High cytokine producers including IL-10 from $\mathrm{CD} 4^{+}$ T-cells and IFN- $\gamma$ from $\mathrm{CD}^{+}{ }^{+} \mathrm{T}$-cells (Figure 5A top panel).

No differences were observed in the frequency of Low and High producers between control and stimulated cultures from IND (Figure 4A and B, top panel).

\section{Impact of bz-treatment of the frequency of low and high cytokine-producers amongst indeterminate chagas disease patients}

Aiming to further apply the concept of Low and High cytokine producers, we investigate the cytokine profile after Bz-chemotherapy in patients with Indeterminate Chagas disease (Figure 5A and B, bottom panels).

Data analysis further confirmed the broad cytokine down-regulation in both innate and adaptive immunity compartment after Bz-treatment (Figure 5A bottom panel).

Upon in vitro antigen stimulation, the leucocytes from INDt were able to shift the down-regulated cytokine 
(A)

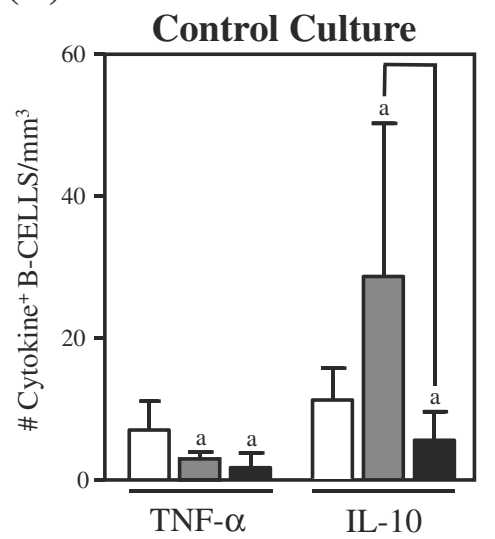

(B)

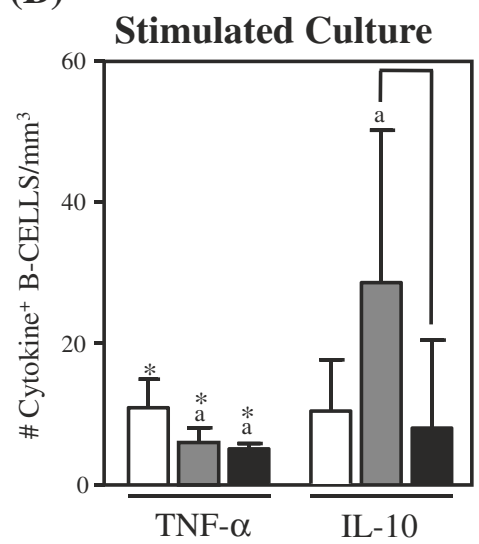

Figure 4 Analysis of intracytoplasmic cytokine profile of B-cells in the peripheral blood from untreated. Indeterminate chagasic patients (IND gray rectangle), Bz-treated Indeterminate chagasic patients (INDt black rectangle) as compared to non-infected individual (NI empty rectangle). Data are expressed as median absolute counts plus the interquartile range of cytokine ${ }^{+}$cells observed after short-term in vitro "Control Culture" (left panel) and T. cruzi epimastigote antigen "Stimulated Culture" (right panel) of whole-blood samples. Cytokine ${ }^{+}$B-cells were quantified by dual color immunophenotyping (anti-CD19-TC plus anti-cytokine-PE mAbs) using specific gate strategy, as described in Material and Methods. The significant differences at $\mathrm{p}<0.05$ for comparisons with $\mathrm{NI}$ are indicated by the letter ' $a$ '. The significant differences at $p<0.05$ for comparisons with INDt are indicated by connecting lines. The significant differences at $p<0.05$ for comparative analysis between "Control" and "Stimulated" cultures are indicated by *.

profile toward a type 1 modulated pattern, characterized by enhanced frequency of High cytokine producers including IFN- $\gamma$ from NK-cells and TNF- $\alpha$ and IFN- $\gamma$ from $\mathrm{CD}^{+}$T-cell along with IL-12 and IL-10 from monocytes (Figure 5A and B, bottom panels).

\section{Discussion}

The first insight to use trypanocidal chemotherapeutic drugs in patients with Chagas disease started almost eighty years ago [19]. However, at the present, only $\mathrm{Nfx}$ and $\mathrm{Bz}$ are clinically available worldwide for the etiological treatment of Chagas disease, with the latter been the main anti-parasitic drug used in Brazil. Despite the effectiveness of $\mathrm{Bz}$ to parasite eradication during acute phase of T. cruzi infection, the limited efficacy during chronic Chagas disease, besides the high frequency of undesirable side effects have contributed to refuse its use to treat over 8 million patients with chronic Chagas disease [5]. Previous reports have shown that, despite the lack of parasite eradication, the etiological treatment contribute to reduce the parasitemia and rearrange the host immune response, leading to balanced inflammatory response crucial to control Chagas disease morbidity $[7,9,13,14,20]$. Regardless these insights, there are still few studies focusing on the immunological changes following Bz-treatment during chronic Chagas disease [13,14,21-23]. A coherent understanding of the immunological following Chagas disease etiological treatment will certainly contribute to determine new perspectives for immunoprevention, therapy, intervention and management [24,25]. In this context, it is important to mention that the development of longitudinal studies would be the choice to avoid possible experimental bias due to particular features of the individual immune response. However, longitudinal interventions presents besides the difficulty to establish long-term follow-up of patients, a large gap between the first and the second evaluation, especially when focusing on long-lasting features, that would introduce a relevant variable to the experimental approaches, mainly due to the reagent lots and equipment performances.

In this study, we have performed a cross-sectional investigation to verify whether the Bz-therapy would induce a long-lasting impact on the immunological status of treated patients leading to a Type- 1 modulated cytokine profile likely that observed early after the end of the treatment $[13,14]$. For this purpose, we have first characterized the cytokine profile of circulating leucocytes from untreated IND patients in order to establish a baseline to evaluate the impact of etiological treatment during chronic T. cruzi infection.

Our data showed that untreated IND patients presented in the ex vivo analysis (Control Culture) an overall type-1 regulated cytokine profile in the innate immune compartment (IL-10 from neutrophils, IL-12 and IL-10 from monocytes and IFN- $\gamma$ from NK-cells) and a predominant type- 2 profile in the adaptive immunity cells (IL-4 from CD4 ${ }^{+}$T-cells, IL-10 from $\mathrm{CD}^{+}$ T-cells and B-lymphocytes). It was interesting to notice that the cytokine profile of innate and adaptive immunity cells was generally preserved upon in vitro antigenic stimulation. 

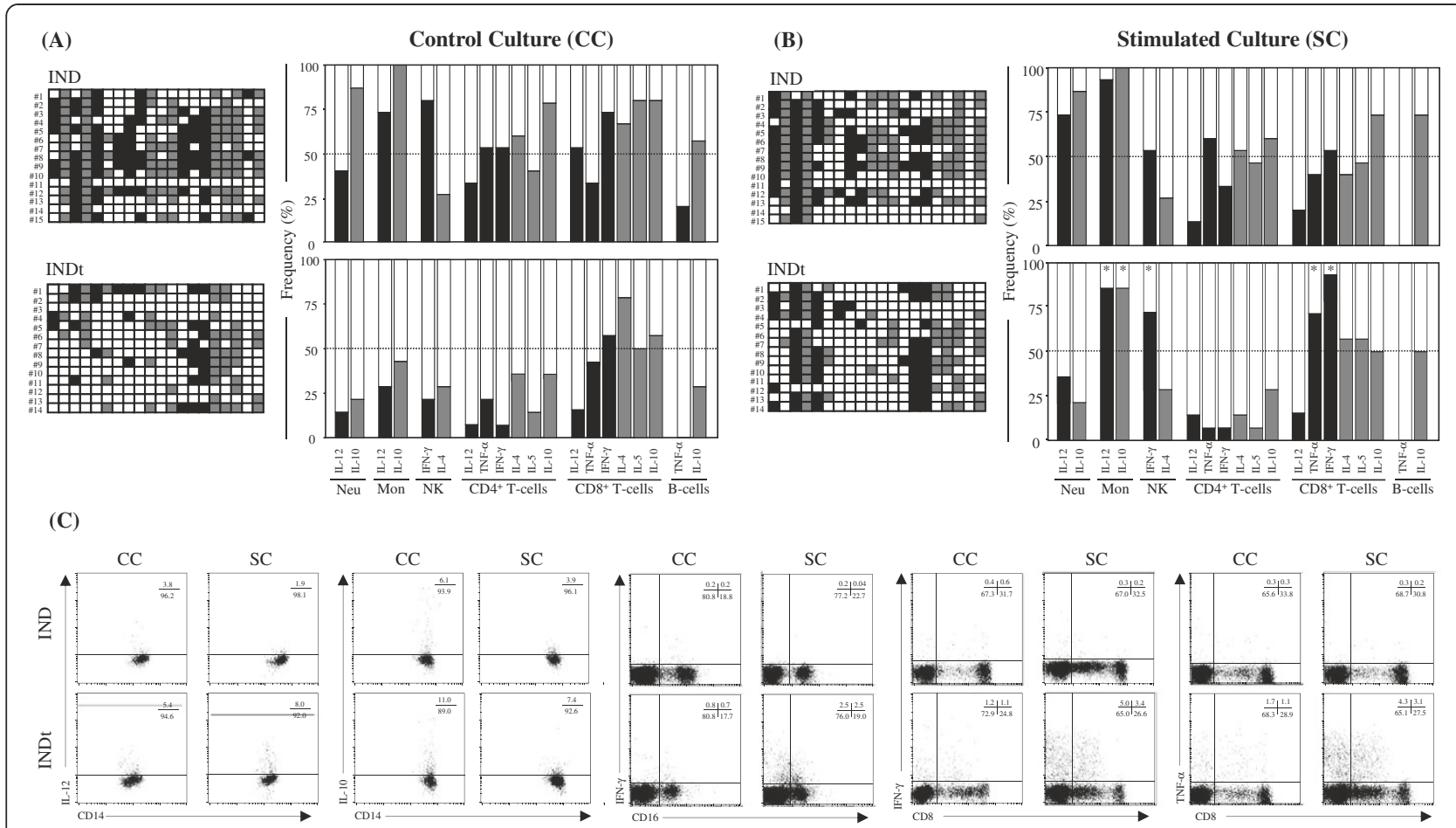

Figure 5 Frequency of low cytokine-producers (empty rectangle). High inflammatory cytokine-producers (black rectangle) and high regulatory cytokine-producers (gray rectangle) for each leukocyte subset in the peripheral blood from untreated Indeterminate chagasic patients (IND) and Bz-treated Indeterminate chagasic patients (INDt) using the median percentage of cytokine ${ }^{+}$cells from the group of non-infected individuals as the cut-off edge. Color diagrams (left panels) were first assembled for individual samples to further compile the resultant frequency (right panels) of cytokine producers in the "Control Culture" (A) and T. cruzi epimastigote antigen "Stimulated Culture" (B) of whole-blood samples. Statistical significance at $\mathrm{p}<0.05$ for comparisons between "Control" and "Stimulated" cultures are represented by *. (C) Representative dot plots illustrating the overall cytokine down-regulation after Bz treatment, as well as the in vitro antigen stimulation shifted the cytokine profile toward a type 1-modulated profile.

These findings showed that untreated IND patients are able to mount a pro-inflammatory cytokine response supported by enhanced levels of IL- $12^{+}$monocytes and IFN $-\gamma^{+}$NK-cells. However, this inflammatory response seems to be regulated in Indeterminate clinical form, to consequently prevent the disease progression, by the establishment of modulatory mechanisms that involve the participation of IL-10 from neutrophils, monocytes, CD8 ${ }^{+}$ T-cells and B-cells. Our findings showed an increased frequency of inflammatory-like monocytes and NK-cells, together with high levels of regulatory-like monocytes and modulated adaptive immunity that could be important to the establishment/maintenance of asymptomatic chronic Chagas disease. Previous studies have shown that the establishment of an inflammatory immune response mediated by monocytes and NK-cells are essential to control T. cruzi infection [26,27] and that the ability to mount immunoregulatory mechanisms in both innate [28] and adaptive immunity [19] are essential to control the inflammatory immune activity and are apparently necessary to prevent a deleterious effect of anti-T. cruzi immune response during asymptomatic chronic Chagas disease.
The analysis of High and Low cytokine producers has been proposed by Bahia-Oliveira et al. [17] and further applied by Vitelli-Avelar et al. [18] to evaluate the cytokine profile of Chagas disease patients. Using this approach, our data further confirmed the cytokine profile described above. Additionally, our findings pointed out the presence of increased frequency of High IL-10 producers within $\mathrm{CD} 4{ }^{+} \mathrm{T}$-cells, but still lower than the frequency of High IL-10 producers within monocytes. These data re-inforce previous reports form Gomes et al., [28] demonstrating that in IND the majority of the IL-10-producing cells are monocytes. Moreover, our data showed that enhanced frequency of High IFN- $\gamma$ producers could be identified within $\mathrm{CD}^{+} \mathrm{T}$-cells in IND, not detectable by the conventional analysis. This finding is also in agreement with those presented by Gomes et al. [28] showing that around 60\% of the IND could be identified as High IFN- $\gamma$ producers. These authors suggested that the IND patients that are high IFN- $\gamma$ producers are candidates to develop cardiomyopathy sooner than those lower producers. On the other hand, it is possible that IND patients who are able to always keep high levels of 
IL-10 secretion has less chance to develop cardiac disease [28]. Human longitudinal studies under evaluation by our group will be able to validate this hypothesis.

As IND is not necessarily a permanent clinical form, with approximately $36 \%$ of them eventually developing severe cardiac disease [1], any effort that could make to maintain the IND clinical status, apart from parasitological cure, would be relevant to control Chagas disease morbidity. It has been suggested that the etiological treatment could be employed to maintain the stable Indeterminate clinical form and prevent the disease progression, despite the parasitological cure [7-9,21]. Since impairment in the cytokine network has been pointed out as one of the determining factors driving disease morbidity $[2,18]$, it is possible that if the etiological treatment would be able to introduce changes in the cytokine network towards immunodulatory mechanisms, it could contribute to prevent the disease progression. In this study, we have characterized the cytokine profile of circulating leucocytes from treated INDt patients, seven years after the end of Bz chemotherapy and compared with that observed in untreated IND patients.

Our data showed that treated INDt patients presented, in the ex vivo analysis (Control Culture), an overall downregulated cytokine profile in both, innate immunity (IL-12 and IL-10 from neutrophils and monocytes besides IFN- $\gamma$ from NK-cells) and adaptive immune compartment (IL-12, TNF- $\alpha$, IFN- $\gamma$ and IL-5 from CD4 $4^{+}$T-cells and IL-10 from B-cells), along with basal levels of cytokine-expressing cells within $\mathrm{CD}^{+}{ }^{+}$T-lymphocytes. The overall down-regulation in the cytokine synthesis observed seven years after the end of Bz-treatment is in agreement with previous reports the immunomodulatory effect of $\mathrm{Bz}$ in experimental models $[21,29,30]$. This modulated profile may account for the general hypothesis that the Bz-treatment during chronic Chagas disease may has a supportive impact, modulating the inflammatory cytokine profile of peripheral blood leucocytes from IND reducing the chances of progression to cardiac disease $[13,14,21]$. However, this down-regulation in the cytokine profile may shortly favor the parasite replication from residual inflammatory foci, considering the low effectiveness of Bz-treatment to promote parasite clearance during chronic Chagas disease [31-33]. To investigate the possible impact that residual T. cruzi antigens would have on the immune response of Bz-treated INDt patients, we have characterized the cytokine pattern triggered upon in vitro $T$. cruzi antigen stimulation. Interestingly, our data showed that the cytokine profile of innate and adaptive immunity cells was greatly impacted by the antigenic stimulation. In fact, the in vitro antigen stimulation was able to emerge the cytokine synthesis mainly in monocytes (IL-12 and IL-10), NK-cells (IFN- $\gamma$ ) and CD8 ${ }^{+}$T-cells (IFN- $\gamma$ ), characterizing an overall type 1-modulated immune profile. The analysis of High and Low cytokine producers further confirmed the impact of T. cruzi antigens on the cytokine pattern of INDt. This modulated pro-inflammatory cytokine pattern resemble that observed in children treated during early Indeterminate Chagas disease (E-INDt), by the ability of NK-cells and $\mathrm{CD}^{+}$T-cells to produce IFN- $\gamma$ [14]. However, there was a major difference regarding the source of modulatory IL-10 in INDt (monocytes) and E-INDt (CD4 ${ }^{+} \mathrm{T}$-cells and B-lymphocytes) [14].

The ability of the immune system to generate stable memory $\mathrm{CD}^{+}{ }^{+}$T-cell after pathogen clearance during acute and chronic infection have been already shown in experimental $T$. cruzi infection [21,34]. These authors have shown that Bz-induced cure drives conversion of the immune response to a stable and protective $\mathrm{CD}^{+} \mathrm{T}$-cell central memory response, capable of showing effector function and providing protective immunity upon re-challenge $[21,34]$. In agreement with our data, the Bz-treatment does not result in the full retention of $\mathrm{CD} 4^{+} \mathrm{T}$-cells able to recall cytokine production upon antigenic stimulation [21]. It has been shown that Bz-treatment of infected hosts leads to a selective expansion of effector and memory $\mathrm{CD} 8^{+} \mathrm{T}$-cells able to protect the hosts against re-infection. These findings allow these authors to hypothesize that besides the direct role in blocking the parasite replication in vivo, Bztreatment appears to positively affect the antigen-driven host immune system and thus maintain the participation of immuneprotective effector mechanism in the antipathogen response. Therefore, the effectiveness of any chemotherapy protocols should consider not only the trypanocidal effect but also its impact on the host immune response.

Additional studies are still needed to better understand the impact of Bz-treatment on the immune system of patients at distinct clinical forms of Chagas disease. As previously reported, we are currently investigating the impact of Bz-treatment on the immunological status on cardiac Chagas disease patients [14]. Preliminary data have pointed out the beneficial impact of Bz-treatment in the immunological profile in cardiac patients increasing the frequency of $\mathrm{IL}-10^{+}$monocytes, an important immunomodulatory event to control deleterious antiparasite immune-mediated inflammatory mechanisms [18]. The ability of $\mathrm{Bz}$ to induce the persistence of antigenspecific memory $\mathrm{CD}^{+}{ }^{+} \mathrm{T}$-cells in cardiac patients are currently under evaluation by our group.

\section{Conclusion}

In summary, our findings showed that the Bz treatment of Indeterminate Chagas' disease patients shifts the cytokine patterns of peripheral blood monocytes, NK-cells and $\mathrm{CD}^{+}$T-cells towards a long-lasting Type-1-modulated profile that could be important to the maintenance of a non-deleterious immunological microenvironment. 


\section{Competing interests}

The authors have no competing interests to declare.

\section{Authors' contributions}

SMES and EDG were responsible for the medical screening of patients. OAMF, RSA, DMVA and ATC were involved in the design, acquisition data and analysis. All authors contributed to the interpretation data. OAMF, RSA, DMVA, SMES and ATC drafted the manuscript and all authors revised the final draft critically for important critical content. All authors have given final approval of the version to be published.

\section{Acknowledgements}

We are thankful to FAPEMIG (APQ-01657-09), CNPq (\#478034/2006-7) grant agencies and FIOCRUZ (PAPES V - \# 403518/2008-3) for the financial support. We are also thank the Program for Technological Development in Tools for Health-PDTIS-FIOCRUZ for use of its facilities. RSA, ATC and OAMF are grateful for FAPEMIG and CNPq research fellowship (PDJ, PQ and PQ, respectively).

\section{Author details \\ ${ }^{1}$ Laboratório de Biomarcadores de Diagnóstico e Monitoração, CPqRR- FIOCRUZ, Belo Horizonte, MG, Brazil. Unicentro Newton Paiva, Belo Horizonte, MG, Brazil. ${ }^{3}$ Universidade Vale do Rio Verde, UninCor, Belo Horizonte, MG, Brazil. "Departamento de Medicina Preventiva e Social, Faculdade de Medicina, Universidade Federal de Minas Gerais, Belo Horizonte, Minas Gerais, Brazil. ${ }^{5}$ Departamento de Propedêutica Complementar, Faculdade de Medicina, Universidade Federal de Minas Gerais, Belo Horizonte, Minas Gerais, Brazil. '́Laboratório de Biomarcadores de Diagnóstico e Monitoração, R, Laboratório de Biomarcadores de Diagnóstico e Monitoração, CPqRR-FIOCRUZ, Av. Augusto de Lima 1715, 30190-002Belo Horizonte, MG, Brazil.}

\section{Received: 13 February 2012 Accepted: 1 May 2012}

Published: 24 May 2012

\section{References}

1. World Health Organization: New global effort to eliminate Chagas disease. Weekly Epidemiol Rec 2007, 82:259-260.

2. Dutra WO, Menezes CA, Villani FN, da Costa GC, da Silveira AB, Reis D, Gollob KJ: Cellular and genetic mechanisms involved in the generation of protective and pathogenic immune responses in human Chagas disease. Mem Inst Oswaldo Cruz 2009, 104:208-218.

3. Urbina JA: Ergosterol biosynthesis and drug development for Chagas disease. Mem Inst Oswaldo Cruz 2009, 104:311-318.

4. de Andrade AL, Zicker F, de Oliveira RM, Almeida Silva S, Luquetti A, Travassos LR, Almeida IC, de Andrade SS, de Andrade JG, Martelli CM: Randomised trial of efficacy of benznidazole in treatment of early Trypanosoma cruzi infection. Lancet 1996, 343:1407-1413.

5. Secretaria de Vigilância em Saúde do Ministério da Saúde: Consenso brasileiro em doença de Chagas. Revista Soc Bras Med Trop, 38:1-29.

6. Sosa Estani S, Segura EL, Ruiz AM, Velazquez E, Porcel BM, Yampotis C: Efficacy of chemotherapy with benznidazole in children in the indeterminate phase of Chagas' disease. AmJTrop Med Hyg 1998, 59:526-529.

7. Garcia S, Ramos CO, Senra JF, Vilas-Boas F, Rodrigues MM, Campos-deCarvalho AC, Ribeiro-Dos-Santos R, Soares MB: Treatment with benznidazole during the chronic phase of experimental Chagas' disease decreases cardiac alterations. Antimicrob Agents Chemother 2005 49:1521-1528.

8. Sosa-Estani S, Segura EL: Etiological treatment in patients infected by Trypanosoma cruzi: experiences in Argentina. Curr Opin Infect Dis 2006, 19:583-587.

9. Viotti R, Vigliano C, Lococo B, Bertocchi G, Petti M, Alvarez MG, Postan M, Armenti A: Long-term cardiac outcomes of treating chronic Chagas disease with benznidazole versus no treatment: a nonrandomized trial. Ann Intern Med 2006, 144:724-734.

10. Pérez-Molina JA, Pérez-Ayala A, Moreno S, Fernández-González MC, Zamora J, López-Velez R: Use of benznidazole to treat chronic Chagas' disease: a systematic review with a meta-analysis. J Antimicrob Chemother 2009, 64:1139-1147
11. Michailowsky V, Murta SM, Carvalho-Oliveira L, Pereira ME, Ferreira LR, Brener Z, Romanha AJ, Gazzinelli RT: Interleukin-12 enhances in vivo parasiticidal effect of benznidazole during acute experimental infection with a naturally drug-resistant strain of Trypanosoma cruzi. Antimicrob Agents Chemother 1998, 42:2549-2556.

12. Rassi A, Amato Neto V, de Siqueira AF, Ferriolli Filho F, Amato VS, Rassi Júnior A: Protective effect of benznidazole against parasite reactivation in patients hronically infected with Trypanosoma cruzi and treated with corticoids for associated diseases. Rev Soc Bras Med Trop 1999, 32:475-482.

13. Sathler-Avelar R, Vitelli-Avelar DM, Massara RL, de Lana M, Pinto Dias JC, Teixeira-Carvalho A, Elói-Santos SM, Martins-Filho AO: Etiological treatment during early chronic indeterminate Chagas disease incites an activated status on innate and adaptive immunity associated with a type 1modulated cytokine pattern. Microbes Infect 2008, 10:103-113.

14. Sathler-Avelar R, Vitelli-Avelar DM, Massara RL, Borges JD, Lana M, TeixeiraCarvalho A, Dias JC, Elói-Santos SM, Martins-Filho OA: Benznidazole treatment during early-indeterminate Chagas' disease shifted the cytokine expression by innate and adaptive immunity cells toward a type 1-modulated immune profile. Scand J Immunol 2006, 64:554-563.

15. Fundação Nacional de Saúde: Tratamento etiológico da doença de ChagasBrasília. Coordenação de controle de doenças transmitidas por vetoresgerência técnica de doença de Chagas. 2nd edition. Rio de Janeiro, Brazil: Fundação Nacional de Saúde; 32.

16. Lowry $\mathrm{OH}$, Rosenbrough M, Farr AL, Randall RJ: Protein measurement with the folin phenol reagent. J Biol Chem 1951, 193:265-275.

17. Bahia-Oliveira LM, Gomes JA, Rocha MO, Moreira MC, Lemos EM, Luz ZM, Pereira ME, Coffman RL, Dias JC, Cançado JR, Gazzinelli G, Corrêa-Oliveira R: IFN-gamma in human Chagas' disease: protection or pathology? Braz J Med Biol Res 1998, 31:127-131.

18. Vitelli-Avelar DM, Sathler-Avelar R, Teixeira-Carvalho A, Pinto Dias JC, Gontijo ED, Faria AM, Elói-Santos SM, Martins-Filho OA: Strategy to assess the overall cytokine profile of circulating leukocytes and its association with distinct clinical forms of human Chagas disease. Scand J Immunol 2008, 68:516-525

19. Mazza S, Montana A, Benitez C, Janzi EZ: Transmission del Schizotrypanum cruzi al niño por leche de la madre con enfermedad de Chagas. Mepra, Mision de Estudios de Patologia Regional Argentina 1936, 28:41-46.

20. Viotti R, Vigliano C, Armenti H, Segura E: Treatment of chronic Chagas' disease with benznidazole: clinical and serologic evolution of patients with long-term follow-up. Am Heart J 1994, 127:151-162.

21. Bustamante JM, Bixby LM, Tarleton RL: Drug-induced cure drives conversion to a stable and protective $C D 8^{+} \mathrm{T}$ central memory response in chronic Chagas disease. Nat Med 2008, 14:542-550.

22. Dutra WO, da Luz ZM, Cançado JR, Pereira ME, Brigido-Nunes RM, Galvão LM, Colley DG, Brener Z, Gazzinelli G, Carvalho-Parra JF: Influence of parasite presence on the immunologic profile of peripheral blood mononuclear cells from chagasic patients after specific drug therapy. Parasite Immunol 1996, 18:579-585.

23. Laucella SA, Postan M, Martin D, Hubby Fralish B, Albareda MC, Alvarez MG, Lococo B, Barbieri G, Viotti RJ, Tarleton RL: Frequency of interferongamma -producing $T$ cells specific for Trypanosoma cruzi inversely correlates with disease severity in chronic human Chagas disease. J Infect Dis 2004, 189:909-918.

24. Quijano-Hernandez I, Dumonteil E: Advances and challenges towards a vaccine against Chagas disease. Hum Vaccin 2011, 7:1184-1191.

25. Vázquez-Chagoyán JC, Gupta S, Garg NJ: Vaccine development against Trypanosoma cruzi and Chagas disease. Adv Parasitol 2011, 75:121-146.

26. Brener Z, Gazzinelli RT: Immunological control of Trypanosoma cruzi infection and pathogenesis of Chagas' disease. Int Arch Allergy Immunol 1997, 114:103-110.

27. Golgher D, Gazzinelli RT: Innate and acquired immunity in the pathogenesis of Chagas disease. Autoimmunity 2004, 37:399-409.

28. Gomes JA, Bahia-Oliveira LM, Rocha MO, Martins-Filho OA, Gazzinelli G, Correa-Oliveira R: Evidence that development of severe cardiomyopathy in human Chagas' disease is due to a Th1-specific immune response. Infect Immun 2003, 71:1185-1193.

29. Piaggio E, Roggero E, Pitashny M, Wietzerbin J, Bottasso OA, Revelli SS: Treatment with benznidazole and its immunomodulating effects on Trypanosoma cruzi-infected rats. Parasitol Res 2001, 87:539-547.

30. Revelli S, Le Page C, Piaggio E, Wietzerbin J, Bottasso O: Benznidazole, a drug employed in the treatment of Chagas' disease, down-regulates the 
synthesis of nitrite and cytokines by murine stimulated macrophages. Clin Exp Immunol 1999, 118:271-277.

31. Camandaroba EL, Reis EA, Gonçalves MS, Reis MG, Andrade SG: Trypanosoma cruzi: susceptibility to chemotherapy with benznidazole of clones isolated from highly resistant Colombian strain. Rev Soc Bras Med Trop 2003, 36:201-209.

32. Cançado JR: Long term evaluation of etiological treatment of chagas disease with benznidazole. Rev Inst Med Trop 2002, 44:29-37.

33. Toledo MJ, Bahia MT, Veloso VM, Carneiro CM, Machado-Coelho GL, Alves CF, Martins HR, Cruz RE, Tafuri WL, Lana M: Effects of specific treatment on parasitological and histopathological parameters in mice infected with different Trypanosoma cruzi clonal genotypes. J Antimicrob Chemother 2004, 53:1045-1053.

34. Olivieri BP, Cotta-De-Almeida V, Araujo-Jorge T: Benznidazole treatment following acute Trypanosoma cruzi infection triggers $C D 8^{+} T$-cell expansion and promotes resistance to reinfection. Antimicrob Agents Chemother 2002, 46:3790-3796.

doi:10.1186/1471-2334-12-123

Cite this article as: Sathler-Avelar et al: Blood leukocytes from benznidazole-treated indeterminate chagas disease patients display an overall type-1-modulated cytokine profile upon short-term in vitro stimulation with trypanosoma cruzi antigens. BMC Infectious Diseases 2012 $12: 123$

\section{Submit your next manuscript to BioMed Central and take full advantage of:}

- Convenient online submission

- Thorough peer review

- No space constraints or color figure charges

- Immediate publication on acceptance

- Inclusion in PubMed, CAS, Scopus and Google Scholar

- Research which is freely available for redistribution 